\title{
Transformações técnico-podutivas e comerciais na pecuária de corte brasileira a partir da década de 90
}

\author{
Luciano Eduardo Morello Polaquini ${ }^{1}$, José Gilberto de Souza ${ }^{2}$, José Jorge Gebara ${ }^{2}$
}

\author{
${ }^{1}$ Mestre em Zootecnia - Universidade Estadual Paulista, Jaboticabal. \\ ${ }^{2}$ Departamento de Economia Rural - Universidade Estadual Paulista, Jaboticabal.
}

RESUMO - Analisou-se o perfil da pecuária de corte brasileira diante das mudanças ocorridas no sistema de produção/ comercialização, observando-se especificamente os índices zootécnicos e produtivos e os volumes de carne produzidos, consumidos e exportados a partir de 1990. Foram analisados dados de trabalhos científicos e de artigos técnicos publicados em jornais e revistas, além de informações veiculadas pela internet. Considerando os resultados obtidos, pode-se inferir que o país apresenta significativo potencial de expansão das exportações de carne bovina, o que exige ajustes internos, que envolvem aspectos sanitários, políticas setoriais e visão mais sistêmica de cadeia produtiva. Destaca-se que esses aspectos ganharam maior importância após a consolidação do Mercado Comum do Sul (Mercosul), quando as relações comerciais se intensificaram e as reações da produção nacional impediram inflexões na estrutura comercial de carne bovina nos mercados interno e externo.

Palavras-chave: bovinocultura de corte, blocos econômicos, exportação de carne bovina, mercosul, produção e consumo de carne bovina

\section{Changes in the Brazilian beef cattle production and commercialization system post-Mercosul}

\begin{abstract}
The objective of this study was to analyze the situation of the beef cattle industry in Brazil after changes in the production/commercialization system with the Mercosul advent. It was closely investigated not only beef cattle production indexes but also amounts of meat produced, consumed, and exported after 1990. Results showed that Brazil has potential to increase meat exportation but that will depend of actions channeled to improve herd sanitary conditions, political issues, and overall production efficiency.
\end{abstract}

Key Words: beef cattle, beef exportation, economic groups, Mercosul, production, meat consumption

\section{Introdução}

O Mercosul evoluiu a partir de um processo de aproximação econômica entre Brasil e Argentina, que teve início em meados dos anos 80. Esse processo pode ser descrito na seguinte ordem cronológica:

- 1985 - firmado pelos presidentes do Brasil e da Argentina um acordo de integração conhecido como "Declaração de Iguaçu";

- 1986 - assinada a Ata para a Integração ArgentinoBrasileira e instituído o Programa de Integração e Cooperação Econômica - PICE entre os dois países, tendo-se como princípios: flexibilidade (para permitir ajustes no ritmo e objetivos), gradualismo, simetria (para que houvesse harmonização de políticas específicas que interferem na competitividade setorial) e equilíbrio dinâmico (para proporcionar integração setorial uniforme);

- 1988 - assinado o Tratado de Integração, Cooperação e Desenvolvimento Argentino-Brasil, além de diversos pro- tocolos (24 no total) envolvendo temas como bens de capital, trigo, cooperação nuclear, transporte marítimo, entre outros.

- Julho 1990 - firmada Ata de Buenos Aires, fixando para janeiro de 1995 o início da vigência de um mercado comum entre os países.

- Dezembro 1990 - consolidados todos os protocolos supracitados em um único instrumento, denominado Acordo de Complementação Econômica - ACE 14, que consistiu em um referencial para o posterior Tratado de Assunção.

- 26/03/1991 - firmado o Tratado de Assunção, entre Argentina, Brasil, Paraguai e Uruguai, para constituição do Mercado Comum do Sul - Mercosul, visando à consolidação de um mercado comum entre os países envolvidos, expressa por meio de: a) livre circulação de bens, serviços e fatores produtivos; b) eliminação das restrições incidentes sobre comércio recíproco; c) estabelecimento de uma tarifa externa comum (TEC); d) adoção de políticas comerciais comuns face a terceiros países; e) coordenação de políticas macroeconômicas e setoriais. 
O desencadeamento de acordos entre os países membros do Mercosul promoveu mudanças em todo o sistema de produção de bovinos de corte no Brasil, sobretudo os setores técnico, sanitário e de comercialização.

Considerando as mudanças na economia brasileira ocasionadas pela implantação do Mercosul, analisaram-se as alterações no padrão técnico-produtivo da pecuária de corte brasileira, correlacionando-as aos índices zootécnicos e produtivos da pecuária de corte e aos volumes de carne produzidos, consumidos e exportados antes e após 1990.

\section{Material e Métodos}

Realizou-se uma revisão bibliográfica baseada em levantamentos censitários do IBGE, anuários estatísticos, teses e outras fontes encontradas na literatura consultada. Neste estudo, são apresentadas inicialmente considerações sobre as relações comerciais do Mercosul, seguidas de um quadro da relação setorial no mercado de carnes e da situação produtiva no Brasil e, finalmente, de uma abordagem sobre mercados e alterações nos cenários nacional e internacional que ilustram a expansão do setor.

\section{Resultados e Discussão}

Considerando a integração de modo geral, o Mercosul produziu efeito esperado, com larga expansão do comércio regional. Contudo, segundo Carvalho (1999), a esperada invasão dos produtos industriais brasileiros nos mercados parceiros não ocorreu, constatando, ao contrário, crescimento acelerado de suas importações, explicado, em parte, pela valorização da moeda nacional brasileira em relação à dos países vizinhos (taxa de câmbio valorizada). Relativamente, o Brasil teve impacto menor nas trocas de produtos agropecuários que dos demais produtos (Tabela 1).

Pecuaristas e agricultores brasileiros afirmam que a criação do Mercosul tem se mostrado positiva, por acreditarem que é produtiva a constituição de um mercado comum do cone sul, mas também são unânimes em reivindicara redução da carga tributária e criticam o baixo desempenho dos empresários em obter ganhos de produtividade. Produzir de forma competitiva é fundamental, diante da abertura de um mercado que ultrapassa as fronteiras de Brasil, Uruguai e Paraguai, ou seja, que vai muito além, atingindo os países da Europa e da Ásia (Brandão et al., 1998).

O resultado da integração em um setor específico depende do que tem ocorrido simultaneamente em outros setores, pois os diversos segmentos produtivos de uma economia possuem relações de interdependência, por exemplo, no fornecimento de insumos.
Brandão et al. (1998), em pesquisa sobre o Mercosul, relataram alguns resultados e destacaram que:

a) o Mercosul é um bloco relativamente pequeno na economia mundial e, portanto, as mudanças nos índices de preços mundiais são insignificantes;

b) a estimativa de ganho com o bem-estar do Mercosul, em renda, da Argentina é de US\$ 713 milhões (aproximadamente $0,3 \%$ PIB), enquanto a do Brasil é de US\$ 3.080 milhões (em torno de $0,6 \%$ PBI). Logo, o ganho absoluto brasileiro é mais que o quádruplo do argentino; e

c) a implementação completa da TEC e da liberalização do comércio intra-regional no âmbito do Mercosul, que ocorrerá até 2006, não produzirá mudanças significativas nos agregados econômicos, de modo que o PIB do Brasil crescerá $0,69 \%$ e o da Argentina praticamente não sofrerá alteração.

Carvalho (1999) afirma que a maior eficiência brasileira no comércio Intra Mercosul é evidenciada pelas diferenças no ritmo de crescimento das exportações e importações, em relação aos demais países do mundo. Como exemplo, no ano de 1992, primeiro ano após o Tratado de Assunção, as receitas das exportações brasileiras destinadas ao Mercosul cresceram $117 \%$ até 1998 . No mesmo período, as exportações para o resto do mundo aumentaram apenas $31 \%$, indicando que o crescimento das exportações para o Mercosul foi 3,5 vezes o das exportações para o resto do mundo.

No caso das importações, a diferença de desempenho foi maior ainda, pois o valor de compras no Mercosul foi o dobro das realizadas nos demais países do mundo. Entre 1992 e 1998, verificou-se expansão de 323\% nas despesas realizadas no Mercosul e de $163 \%$ nas realizadas em outros países (Carvalho, 1999)

Segundo Rodrigues \& Jank (1993), citados por Carrer (2000), o impacto do Mercosul inicialmente ocorreria de forma diferenciada, de acordo com a região geográfica e a estrutura produtiva utilizada, com maiores alterações concorrenciais nas propriedades da Região Sul do Brasil, especialmente as menos eficientes, que trabalham em baixa escala e com baixo nível tecnológico, e em algumas propriedades das regiôes Centro-Oeste e Pré-amazônica, que têm sua produção inviabilizada para exportação, principalmente em razão da distância, do câmbio desfavorável e dos tributos.

No Brasil, a fase inicial da modernização da pecuária de corte ocorreu em meados da década de 70 com a implementação de programas de crédito subsidiados, como o Conselho de Desenvolvimento da Pecuária (CONDEPE), o Programa Nacional de Pastagens (PRONAP) e o Programa 
Tabela 1 - Crescimento brasileiro das exportações e importações para o Mercosul no período de 1992 a 1998

Table 1 - Growth of Brazilian exportation and importation to Mercosul (1992-1998)

\begin{tabular}{lcc}
\hline $\begin{array}{l}\text { Produto } \\
\text { Product }\end{array}$ & $\begin{array}{c}\text { Exportações (\%) } \\
\text { Exportation (\%) }\end{array}$ & $\begin{array}{c}\text { Importações (\%) } \\
\text { Importation (\%) }\end{array}$ \\
\hline $\begin{array}{l}\text { Agropecuários } \\
\begin{array}{l}\text { Agricultural } \\
\text { Demais produtos } \\
\text { Remaining products }\end{array}\end{array}$ & 152 & 193 \\
\hline
\end{tabular}

Fonte: Carvalho (1999).

Source: Carvalho (1999).

Nacional de Desenvolvimento da Pecuária de Corte (PROPEC), que visavam à criação de uma infra-estrutura nas propriedades rurais, para estimular o desenvolvimento do setor (Pinazza \& Alimadro, 2000). Contudo, a melhoria nos índices zootécnicos foram percebidas somente na década seguinte, visto que o ciclo pecuário é muito longo. Nesse processo, houve também a disseminação do uso de sais minerais, vacinas e medicamentos, entre outros insumos, possibilitada pelo Sistema EMATER (Empresa de Assistência Técnica e Extensão Rural) e pela CATI(Coordenadoria de Assistência Técnica Integral do Estado de São Paulo) e com prestação de serviços em prol da difusão de assistência técnica para melhoria da genética, da nutrição, da sanidade e do manejo dos plantéis (Tabela 2).

Em decorrência dos incentivos governamentais, o setor obteve acréscimo de mais de 138 mil novos tratores, além de alguns recursos diretamente correlacionados a tecnologias, melhorando o sistema de produção agropecuário do país. Como exemplo, o número de estabelecimentos que passaram a utilizar calcário cresceu mais de $130 \%$. Quanto à implementação de controle zoosanitário nas propriedades, considera-se pouco provável, no entanto, que o número de estabelecimentos beneficiados com esta tecnologia seja tão alto quanto o estimado ( $82 \%$ ), visto que ainda são notórios problemas sérios, como a ausência de controle de ecto e endoparasitas e a dificuldade em eliminar a febre aftosa em rebanhos (Fundepec, 2000).

Ressalta-se também que ainda é grande o número de estabelecimentos rurais que se beneficiam de créditos; apenas $6 \%$ dos produtores tiveram recursos para alavancar sua produção. No caso da pecuária de corte, especificamente, isso indica que os produtores não têm efetiva capacidade ou estímulos para realizar investimentos como reforma ou implantação de pastagens, aquisição de animais melhorados geneticamente e adequação do sistema de produção às necessidades impostas pelo mercado. Além disso, a euforia do setor agrícola com a abundância e o subsídio do crédito agrícola nas décadas 60 e 70 foi substituída pela decadência do processo de financiamento nos anos de 1975 e 1985. Com demanda muito superior à arrecadação de recursos para o financiamento agrícola, o governo aumentou os “depósitos compulsórios" sobre os depósitos dos bancos comerciais e impôs limites e restrições para novos financiamentos, forçando os produtores à tentativa de recursos junto ao setor privado. De 1977 a 1983, a participação dos bancos federais (Banco do Brasil e Banco Central) em crédito agrícola foi reduzida em mais de $21 \%$, com declínio de $87,4 \%$ para $68,5 \%$ dos recursos aplicados. A participação dos bancos comerciais, no entanto, cresceu de 12,6\% em 1977 para 31,5\% em 1983 (Banco Central do Brasil, citado por Talamini \& Montoya, 2002).

O cenário econômico da década de 80 , que afetou todos os setores da economia, provocou fortes mudanças na agropecuária. O crédito, antes farto e subsidiado, tornou-se escasso e com taxas positivas de juros (Gonzales, 1999).

Na década de 90, ocorreu o acirramento da competição no mercado de carnes; houve implemento na produção de frangos e suínos, com conseqüente mudança nos hábitos alimentares dos brasileiros, registrando-se larga aceitação das carnes de frango e de suínos. Os pecuaristas brasileiros buscaram, então, melhorar seus índices produtivos, para competir, sobretudo, no Mercosul, embora a Argentina e o Uruguai fossem os parceiros mais "eficientes" na produção de carne tipo exportação.

Ao considerar somente as exportações de carne classificadas para a Cota Hilton ${ }^{1}$, observa-se superioridade da Argentina em fornecer carnes nobres e que, em 2002, elevou em mais de 10.000 to valor de sua Cota Hilton, aumentando para 38.000 t a quantidade a ser exportada para a comunidade européia, enquanto a cota brasileira é de apenas $5.000 \mathrm{t}$.

Kruger et al. (1988) indicam que as intervenções indiretas sobre o setor agrícola brasileiro provocaram impacto tão forte quanto o das intervenções diretas. Esses impactos são efeitos de políticas comerciais e macroeconômicas sobre a taxa de câmbio real, que, quando sobrevalorizada, indiretamente penalizou os setores de exportação.

Apesar destas intervenções, a bovinocultura se desenvolveu em quase todos os estados de Brasil, observando-se diferentes sistemas de produção e grandes diferenças nos níveis de produtividade, de acordo com a organização do capital produtivo.

\footnotetext{
${ }^{3}$ Cota Hilton é um prêmio oferecido pela União Européia (EU) aos países que exportam seus melhores cortes de carnes. Pelas regras em vigor, a chamada cota Hilton permite a entrada de 58.100 toneladas de cortes bovinos nobres na EU com uma tarifa de $20 \%$ ad valorem. A Argentina já tem uma cota de 28 mil toneladas. O Brasil é autorizado a vender 5 mil toneladas, os Estados Unidos e Canadá, 11.500 toneladas, a Austrália, 7.000, o Uruguai, 6.300 e Nova Zelândia, 300 toneladas.
} 
Tabela 2 - Brasil: evolução dos indicadores tecnológicos (1985 - 1996)

Table 2 - Brazil: evolution of indicators tecnology (1985 - 1996)

Emprego de tratores

Tractors utilization

Correção do solo

Soil fertilization

Controle zoosanitário

Animal health control

Assistência técnica

Consultant service

Energia elétrica

Energy

Crédito

Credit
138,4 mil tratores $(20,81 \%)$

138.4 mil tractors $(20.81 \%)$

Aumento de 12,6 para $29,8 \%$ dos estabelecimentos

Increase from $12.6 \%$ to $29.8 \%$ of the establishments

Aumento de $37,4 \%$ para $50 \%$ dos estabelecimentos

na bovinocultura, de 59,5 para $82 \%$

Increase from $37.4 \%$ to $50 \%$ of the establishments, in cattle production increase from $59.3 \%$ to $82 \%$

Aumento de $10,7 \%$ para $19,5 \%$ dos estabelecimentos, enquanto

a assistência de fontes governamentais decresce de 52,7 para $40,3 \%$.

Increase of 10.7 to $19.5 \%$ of the establishments

Government assistance reduced from $52.7 \%$ to $40.3 \%$

Acréscimo de apenas $40 \%$

Growth of $40 \%$

Acréscimo de 5,3\% no número de estabelecimentos mantidos

com recursos emprestados; no caso de custeio, o índice de crescimento é de 4,1\%.

Increase of $5.3 \%$ the number of establishments that use this recurse; for cost, the index growth was of $4.1 \%$

Fonte: IBGE, Censos Agropecuários, adaptado por Pinazza \& Alimandro (2000).

Source: IBGE, agricultural census, cited by Pinazza \& Alimandro (2000).

A produção de gado de corte no Brasil envolvia um processo demorado e de baixo rendimento, com média de seis a sete anos da concepção ao abate e proporcionava apenas $16,5 \%$ de lucro, como conseqüência da baixa eficiência reprodutiva na fase de cria e do lento crescimento ponderal na recria. Nas criações extensivas, a natalidade correspondia a 50 e $55 \%$, de modo que as novilhas geravam a primeira cria aos 4 anos e os machos eram abatidos, em média, aos 5 anos e meio de idade (Peetz, 1996).

Alguns dados ilustram com maior clareza o comportamento do setor no início da década de 80 . O rebanho era constituído por pouco mais de 124 milhões de cabeças, com abate anual de 19,6 milhões, produzindo em torno de 3.495 milhões $t$ em equivalente-carcaça. A população brasileira apresentava consumo per capita de carne bovina de aproximadamente $23 \mathrm{~kg} / \mathrm{hab}$.ano. O país exportou $450 \mathrm{mil} \mathrm{t}$ e importou 30 mil t, em equivalente-carcaça. É importante mencionar que na época quase não se confinavam animais, dado evidenciado pelo pequeno número de animais terminados no ano de 1983, algo em torno de 200 mil (Anualpec, 1994).

Nos três primeiros anos da década de 90, a desvalorização da moeda brasileira contribuiu para o crescimento das exportações do Brasil e proporcionou aumento dos investimentos nos setores agropecuários de exportação, como carne bovina, aves e complexo soja (McClain, 1993). No entanto, o Plano Real, empreendido em 1994, provocou novamente a sobrevalorização da moeda, resultando em menores retornos das atividades agropecuárias de exportação e doméstica (Souza, 1998).
Ocorreram, no entanto, muitos fatores concorrenciais que favoreceram o desenvolvimento do setor de carnes no país, que, favorecidos pelas políticas públicas da década anterior, ocasionaram a "modernização" do setor. O desenvolvimento de novas tecnologias por centros de pesquisas, o processo de profissionalização do mercado (desde os fornecedores de insumos até o varejo) e a segmentação da produção (alianças comerciais) e do consumo foram importantes para a cadeia produtiva da bovinocultura de corte brasileira, qualificando-a para os mercados nacional e internacional.

Todos estes fatores determinaram a posição do país como maior rebanho bovino comercial do mundo, com 2 milhões de propriedades e dois em cada três hectares empregados em atividades rurais. Estima-se ainda que a cadeia (insumos, produção animal, indústria e comércio de carnes e couros) emprega diariamente 7,2 milhões de pessoas. Anualmente, são abatidos 32 a 34 milhões de cabeças, movimentando em torno de R $\$ 12$ bilhões, se somadas as receitas com cortes de carne, couro, miúdos e outros subprodutos (Anuário DBO, 2002).

As análises sobre o mercado mundial de carnes do Departamento de Agricultura dos Estados Unidos (USDA) demonstram que, no ano de 2001, a comercialização de carne bovina não foi satisfatória, revertendo ao longo de 2002, com aumentos na exportação que chegaram a 18,5\% em relação ao ano anterior (Anuário DBO, 2003).

Desde a mudança da política cambial nos primeiros meses de 1999, o Brasil vem ganhando espaço no mercado internacional de carne bovina e seus derivados, embora as exportações brasileiras ainda representem apenas um pouco 
mais de 11,3\% da produção nacional (Anualpec, 2002). Com valores em ascensão, o país tem melhorado sua posição no cenário mundial (Tabela 3 ) e, pelo levantamento do USDA, pode chegar a $14,1 \%$ da produção dos principais países produtores de carne do mundo em 2002, com uma produção calculada em 6,9 milhões de toneladas em equivalente-carcaça.

Diante deste quadro, a cadeia produtiva passa por uma nova etapa. A diferenciação de produtos, a começar pela classificação de carcaças, e a possível remuneração ao pecuarista pela melhor qualidade certamente têm a produção de carne que atenda aos mercados interno e externo.

Os zebuínos, fundadores do rebanho nacional e normalmente desprezados no contexto mundial, ganharam novo status por sua condição de baixo risco de contaminação da encefalopatia bovina (EEB), evidenciando o potencial do chamado "boi verde".

Os avanços tecnológicos revolucionaram a engorda e a terminação de bovinos de corte, aumentando significativamente o número de animais terminados em confinamento entre 1992 e 2001 (de 825.000 para quase 2 milhões de cabeças terminadas em confinamento). Além disso, com o aprimoramento da terminação de animais semiconfinados (1992 e 250 mil cabeças; 2001 - 2.565 milhões de cabeças) e o desenvolvimento de tecnologias capazes de finalizar, ou mesmo antecipar, a terminação de bovinos de corte sob pastejo (entre os anos de 1992 e 2001), ocorreu acréscimo de mais de 1,2 milhões de cabeças), dispensando o deslocamento de capital para investimentos iniciais em instalações e maquinaria e minimização das despesas administrativas (Anualpec, 2002).

Após o salto tecnológico no processo de intensificação da terminação de bovinos sob pastejo, busca-se a maximização dos resultados econômicos dessa atividade, visto que os avanços tecnológicos, propiciam, ao mesmo tempo, a elevação do número de animais abatidos durante a entressafra e favorecem a redução do diferencial de preços entre a safra e entressafra, em razão da maior oferta de animais no período, estimulando a redução dos custos de produção.

O setor de suplementos minerais e a pecuária brasileira passam por maior exigência quanto à qualidade, à otimização dos custos e à incorporação de sistemas de rastreabilidade, além de medidas que garantam a segurança alimentar, a sustentabilidade na produção e a certificação de origem e produção. O setor produziu, em 2000, quantidade pouco superior a 1 milhão de toneladas; em 2001, mais de 1,3 milhão de toneladas comercializadas; e, em 2002, houve um crescimento no setor em torno de $12,5 \%$. Dados apontavam uma demanda de três milhões de toneladas de suplementos minerais para atender o rebanho nacional, que, na época, seria de 161,8 milhões cabeças (DBO, 2002).

Existem ainda dois fatores que favoreceram diretamente as exportações de produtos brasileiros: a Lei Kandir que, em 1996, desonerou os produtos primários e semimanufaturados do pagamento do imposto sobre circulação de mercadorias e serviços (ICMS) para exportação e a desvalorização da moeda brasileira, em 1999.

Constam na Tabela 4 os dados referentes ao crescimento no setor de bovinocultura de corte nos anos de 1992 a 2002. Os valores crescentes de exportações de carne in natura ao longo do período comprovam que o setor vem passando por uma reestruturação para melhor atender os consumidores da carne brasileira.

Segundo Souza (1998), existe significativa complementaridade de commodities de origem animal, grãos e oleaginosas nos quatro países do Mercosul e, portanto, os ganhos potenciais de uma integração no Cone Sul são evidentes. Waquil (1995) afirma que a integração regional também influencia as ligações de comércio de cada país membro com os demais países do mundo, em razão da melhoria da posição de barganha e, conseqüentemente, do tamanho do mercado. É esperado que o Brasil, a Argentina e o Paraguai coordenem suas exportações de soja e farelo de soja e que os quatro países, juntos, coordenem suas exportações de carne bovina.

Tabela 3 - Distribuição da produção de carne de diferentes países Table 3 - Distribution of meat production of different countries

\begin{tabular}{|c|c|c|c|c|c|}
\hline & \multicolumn{3}{|c|}{$\begin{array}{l}\text { Produção (mil.t.carcaça) } \\
\text { Production (mil.t. carcass) }\end{array}$} & \multicolumn{2}{|c|}{$\begin{array}{c}\text { Consumo (mil. t carcaça) } \\
\text { Consumed (mil. t carcass) }\end{array}$} \\
\hline & 2002 & 2001 & 2000 & 2002 & 2001 \\
\hline Estados Unidos (United States) & 11.626 & 11.955 & 12.298 & 12.025 & 12.356 \\
\hline Brasil (Brazil) & 6.985 & 6.750 & 6.520 & 6.392 & 6.190 \\
\hline União Européia (European Union) ${ }^{\mathrm{c}}$ & 6.932 & 6.896 & 7.462 & 6.897 & 6.433 \\
\hline China & 5.880 & 5.600 & 5.328 & 5.840 & 5.559 \\
\hline Argentina & 2.900 & 2.860 & 2.880 & 2.660 & 2.730 \\
\hline Total mundial (Worldwide total) & 49.352 & 49.093 & 49.775 & 48.791 & 48.1498 \\
\hline
\end{tabular}

Fonte: USAD, outubro/2001, apud Anuário DBO 2002- Adaptado pelo autor

Source: USAD, october/2001, cited by Anuary DBO 2002. 
Tabela 4 - Balanço das exportações e importações brasileiras de carne bovina: 1992 a 2002 (em equivalente-carcaça) Table 4 - Balance of the Brazilian exportation and importation of beef from 1992 to 2002 (in carcass-equivalent)

\begin{tabular}{|c|c|c|c|c|c|c|c|c|}
\hline \multirow[t]{3}{*}{$\begin{array}{l}\text { Ano } \\
\text { Year }\end{array}$} & \multicolumn{4}{|c|}{$\begin{array}{l}\text { Exportação } \\
\text { Exportation }\end{array}$} & \multicolumn{4}{|c|}{$\begin{array}{l}\text { Importação } \\
\text { Importation }\end{array}$} \\
\hline & \multicolumn{2}{|c|}{$\begin{array}{l}\text { Industrializada } \\
\text { Industrialized }\end{array}$} & \multicolumn{2}{|c|}{$\begin{array}{l}\text { In natura } \\
\text { Fresh }\end{array}$} & \multicolumn{2}{|c|}{$\begin{array}{c}\text { Total } \\
\text { Total }\end{array}$} & \multicolumn{2}{|c|}{$\begin{array}{l}\text { Total } \\
\text { Total }\end{array}$} \\
\hline & mil t. ${ }^{1}$ & mil US\$ ${ }^{2}$ & mil t. ${ }^{1}$ & mil US\$ ${ }^{2}$ & mil t. ${ }^{1}$ & mil US\$ ${ }^{2}$ & mil t. ${ }^{1}$ & mil US\$ $\$^{2}$ \\
\hline 1990 & 149 & 141.000 & 100 & 93.000 & 249 & 234.000 & 255 & 176.000 \\
\hline 1991 & 214 & 219.778 & 121 & 212.839 & 335 & 432.617 & 108 & 117.600 \\
\hline 1994 & 274 & 287.465 & 102 & 268.090 & 376 & 555.556 & 86 & 111.739 \\
\hline 1995 & 238 & 292.873 & 49 & 180.780 & 287 & 473.652 & 121 & 169.585 \\
\hline 1996 & 219 & 236.323 & 61 & 194.305 & 280 & 430.628 & 139 & 175.678 \\
\hline 1997 & 219 & 231.816 & 68 & 196.295 & 287 & 428.112 & 112 & 196.553 \\
\hline 1998 & 265 & 296.233 & 105 & 276.595 & 370 & 572.829 & 79 & 156.362 \\
\hline 1999 & 345 & 318.106 & 196 & 443.835 & 541 & 761.941 & 42 & 71.128 \\
\hline
\end{tabular}

Fonte (Source): FNP/SECEX/DECEX.

${ }^{1}$ mil toneladas equivalente-carcaça (thousand $t$ carcass-equivalent); ${ }^{2}$ US $\$ / t$. equivalente-carcaça FOB (U\$/t carcass-equivalent).

Quanto ao Mercosul, o cenário continua desfavorável para o Brasil em relação à sua balança comercial, porém, a partir de 1999 (Tabela 5), o saldo negativo apresentou redução, com inflexão no ano de 2002. Essa redução devese, em parte, ao aumento da competitividade dos produtos brasileiros, ocasionado pela desvalorização do Real no início de 1999, e à adoção de novas tecnologias pelos produtores rurais de modo geral, aumentando consideravelmente as quantidades produzidas e alterando a base de seus custos de produção.

Pode-se inferir que, a partir do ano 2000, o cenário mundial foi muito favorável às exportações brasileiras, em decorrência de alguns acontecimentos, como: o aumento das áreas livres de febre aftosa no Brasil e a implantação de sistemas de controle de carne produzida no país, visando atender às exigências dos mercados externos; as sucessivas crises de abastecimento mundial provocadas pelo aparecimento da encefalopatia espongiforme bovina (EEB) nos rebanhos europeus, que favoreceu a exportação da carne bovina brasileira, por ser quase que exclusivamente originada de animais criados sob sistema de pastejo; e as crises econômicas e sanitárias na Argentina ocasionadas pelo surgimento de surtos de febre aftosa.

Esses fatores foram decisivos para o crescimento das exportações brasileiras e para as alterações na bovinocultura de corte, intra e extra bloco. O Mercosul serviu de estímulo para que o setor produtivo de carne no Brasil se tornasse mais competitivo, visando exportar não somente para os países do bloco, mas principalmente para os demais países do mundo.
Tabela 5 - Balança do agronegócio do Mercosul: 1992 a 2001 (milhões de US\$ - FOB)

Table 5 - Balance of Mercosul agri business from 1992 to 2002 (millions $U \$$ - FOB)

\begin{tabular}{lccc}
\hline $\begin{array}{c}\text { Ano } \\
\text { Year }\end{array}$ & \multicolumn{3}{c}{$\begin{array}{c}\text { Brasil x Mercosul } \\
\text { Brazil x Mercosul }\end{array}$} \\
\cline { 2 - 4 } & $\begin{array}{c}\text { Exportação } \\
\text { Exported }\end{array}$ & $\begin{array}{c}\text { Importação } \\
\text { Imported }\end{array}$ & $\begin{array}{c}\text { Saldo } \\
\text { Balance }\end{array}$ \\
\hline 1990 & 215,4 & $1.677,6$ & $-1.462,1$ \\
1991 & 458,9 & $1.523,0$ & $-1.064,1$ \\
1992 & 694,6 & $1.366,7$ & $-672,1$ \\
1993 & $1.008,2$ & $1.727,7$ & $-719,5$ \\
1994 & $1.084,1$ & $2.451,6$ & $-1.367,5$ \\
1995 & $1.303,5$ & $3.468,4$ & $-2.165,8$ \\
1996 & $1.475,7$ & $3.943,6$ & $-2.467,9$ \\
1997 & $1.697,2$ & $3.830,3$ & $-2.133,1$ \\
1998 & $1.784,8$ & $4.002,0$ & $-2.217,2$ \\
1999 & $1.356,3$ & $2.927,3$ & $-1.571,1$ \\
2000 & $1.153,5$ & $2.912,5$ & $-1.399,0$ \\
2001 & $1.454,3$ & $2.449,5$ & $-995,2$ \\
2002 & 944,9 & $2.461,7$ & $-1.516,8$ \\
\hline
\end{tabular}

Fonte (Source): SECEX/MDIC.

\section{Conclusões}

O Brasil apresenta significativo potencial de expansão para exportação de carne, mas são necesários ajustes internos, aspectos sanitários e uma visão sistêmica da cadeia produtiva.

As transformações ocorridas na pecuária nacional com a implementação do Mercosul foram extremamente importantes uma vez que o livre comércio entre os blocos poderia concorrer com uma inflexão nas bases produtiva e comercial brasileiras, afetando os mercados nacional e internacional de carne bovina. 


\section{Literatura Citada}

ANUALPEC 94: anuário da pecuária brasileira. São Paulo: FNP Consultoria \& Comércio, 1994. p.184-192.

ANUALPEC 2002: anuário da pecuária brasileira. São Paulo: FNP Consultoria \& Comércio, 2002. p.87.

ANUÁRIO DBO 2002: balanço da pecuária em 2001 deixa bom saldo e espaço para crescer. São Paulo: DBO Editores Associados Ltda, 2002. n.256, p.13.

BRANDÃO, A.; SALAZAR, P.; LOPES, M.R. et al. Uma análise quantitativa dos impactos do Mercosul sobre o Brasil. In: BRANDÃO, A.S.P.; PEREIRA, L.V. (Eds.) Mercosul: prespectivas da integração. 3ed. Rio de Janeiro: Fundação Getúlio Vargas, 1998. 308p

CARRER, C.C. Caracterização e diferenciação regional da pecuária de corte no Brasil do fim de século: gênese, modernização e reestruturação produtiva e mercadológica. Campinas: Universidade Estadual de Campinas, 2000. 268p. Tese (Doutorado em Economia) - Universidade Estadual de Campinas, 2000.

CARVALHO, M.A. Comercio agropecuário brasileiro no Mercosul. Informações Econômicas, v.29, n.6, p.7-22, 1999.

FUNDEPEC. Aftosa - uma história que não acabou. Ano VI, n.10, 2000. 58p.

GONZALES, B.R.C. Ao ambientes contratual e operacional da cédula de produto rural (CPR) e interações com os mercados futuros e de opções. Piracicaba: Escola Superior de Agricultura Luiz de Queiroz, 1999. 169p. Tese (Doutorado em Economia Aplicada) - Escola Superior de Agricultura Luiz de Queiroz, 1999.

KRUGUER, A.; SCHIFF, A.; VALDÉS, A. Agricultural incentives in developing countries: measuring the effects of sectoral and economy wide policies. (S.L.): The World Bank Economics Review, 1998. v.3, p.225-71.
McMCLAIN, E. Brazil In: International agriculture and trade report: western hemisphere. Washington, D.C.: USDA/ERS, 1993. p.32-36.

PEETZ, R.M. Cadeia produtiva de carne bovina no estado de São Paulo. São Paulo: Secretaria de Agricultura e Abastecimento, 1996. $51 \mathrm{p}$.

PINAZZA, L.A.; ALIMANDRO, R. Novo mundo rural. Revista agroanályses, v.20, n.4, p.12-26, 2000.

REVISTA DEL MERCOSUL. Como supera Brazil las distorsiones del comercio mundial. n.70, 2001. 130p.

SOUZA, W.A. Determinantes da viabilidade de mercados futuros agropecuários no âmbito do Mercosul. Piracicaba: Escola Superior de Agricultura Luiz de Queiroz, 1998. 136p. Tese (Doutorado em Economia Aplicada) - Escola Superior de Agricultura Luiz de Queiroz, 1998.

TALAMINI, E.; MONTOYA, M.A. Aspectos do crédito agrícola formal e informal na região da produção. In: CONGRESSO BRASILEIRO DE ECONOMIA E SOCIOLOGIA RURAL, 40., 2002, Passo Fundo. Anais... Passo Fundo: 2002. (CD-ROM)

WALQUIL, P.D. Primal-dual spatial equilibrium model with intermediate products: application to the agricultural sector in the Mersocul. Wisconsin: University of Wisconsin 1995. Tese (Ph.D.) - University of Wisconsin, 1995. 